\title{
SHIRLEY JACKSON: UMA APRESENTAÇÃO NECESSÁRIA
}

\author{
Gustavo Vargas Cohen (UFRGS) \\ gustavocohen.ufrgs@yahoo.com
}

\section{Introdução}

Ela escreveu seis romances completos, duas memoirs sobre a vida em família, quatro coleções de contos, quatro livros infantis, uma peça teatral infanto-juvenil, cerca de trinta artigos de não-ficção, numerosas resenhas literárias e aproximadamente uma centena de contos individuais; esta última, a forma literária na qual se provou mais prolífica.

Ela é responsável por uma das histórias de casas assombradas mais importantes da história da literatura americana e mundial, o romance A Assombração da Casa da Colina ${ }^{19}$ (The Haunting of Hill House), publicado em 1959 e adaptado para o cinema em grandes produções pelo menos em três momentos históricos, com ênfase para a versão de 1963, conduzida pelo lendário diretor Robert Wise, e para a versão da DreamWorks de 1999, dirigida por Jan De Bont, e estrelada por Liam Neeson, como o Dr. Montague, Catherine Zeta-Jones, Owen Wilson e Lili Taylor, no papel da protagonista Eleanor Vance.

Escreveu também o que foi, possivelmente, a história mais controversa já impressa na revista americana New Yorker, o conto "A Loteria" (The Lottery). Publicado em 1948, o conto resultou em centenas de cartas abusivas para os editores e para a autora, além de centenas de cancelamentos de assinaturas da revista. "A Loteria" seria, mais tarde, adaptada para a televisão, para o teatro, para o radio e até mesmo, em uma transformação quasi-mística, coreografada em peça de balé.

\footnotetext{
19 Todos os termos, expressões e citações originalmente em língua inglesa foram traduzidos para a língua portuguesa por este autor.
} 
Juntamente com o conto An Occurence at Owl Creek Bridge, de Ambrose Bierce e A Good Man's Hard to Find, de Flannery O'Connor, "A Loteria" fez desta escritora uma entre os três escritores mais antologizados da história literária norte-americana do século XX.

A despeito de sua sólida produção artística e de sua marca indelével na história da literatura, a norte-americana Shirley Jackson (19161965) é hoje considerada uma escritora esquecida. Os motivos para isso são difíceis de discernir, porém não impossíveis. O presente texto é um convite para diligenciar e desvelar este fenômeno.

\section{A Bruxa de North Bennington}

De acordo com a mitóloga Barbara G. Walker "qualquer habilidade incomum em uma mulher instantaneamente levanta a suspeita de bruxaria" (1983: 1078). Embora Jackson não fosse uma bruxa de qualquer sorte, ela possuía uma extensa biblioteca sobre o assunto, e suas tendências agorafóbicas imensamente contribuíram para acentuar a mística que a cercava na pequena cidade de North Bennington, Vermont onde residiu nos últimos anos de vida. Diziam que sua casa era sua caverna, seu círculo social, seu conciliábulo, e os (muitos) gatos domésticos que com ela viviam, seus familiares. Sensacionalistas ou não, rumores de que Shirley possuía poderes sobrenaturais eram constantes. De acordo com o jornalista e romancista americano David Gates "acreditava-se amplamente que [Jackson] havia quebrado a perna do editor Alfred Knopf ao fincar alfinetes em um boneco de vodu" (Apud SULLIVAN, 1994, p. 71). A estudante Elizabeth Frank, da Bennington College onde Shirley trabalhava, lembrou que ouvira "um boato que [Jackson] havia transformado certo membro do corpo docente em uma abóbora" (Idem, p. 71). Uma das orientandas de seu marido Stanley Edgar Hyman, que conheceu Shirley pessoalmente, Joan Schenkar, lembrou em um ensaio para The Wall Street Journal que a primeira informação que se ouvia a respeito da esposa do professor é que ela era uma bruxa. Segundo ela, Jackson tacitamente encorajava este rumor, pois lia cartas de tarô, inseria em seus textos de ficção citações de obras de magia negra e, por fim, dava aos seus gatos (onze ao total), os nomes de duques e demônios do inferno (SCHENKAR, 2010). Como se pode notar, o conjunto de evidências reais aponta para uma condenação que seria admissível em instâncias como, por exemplo, Salem, Massachusetts por volta de 1692. 
A aura sobrenatural que cercava Jackson refletia-se em suas obras e, por razões interessantes, foram estas as mais famosas, justamente as que eram assustadoras e chocantes. Não só, mas principalmente por este motivo ela foi, e tem sido, considerada apenas uma escritora de histórias de horror. A despeito de sua declarada diversidade temática, seus contos que contém elementos góticos e/ou sobrenaturais, de alguma maneira, foram os recebidos pela mídia e pelo público leitor com maior facilidade; muitas vezes, por motivos alheios à vontade da escritora. Por exemplo, em 1983, o escritor Stephen King, em uma entrevista para a revista Playboy, confessou que seu livro O Iluminado (The Shining) "foi influenciado pelo maravilhoso romance de Shirley Jackson The Haunting of Hill House" (Apud NORDEN, 1983, p. 2). Este tipo de publicidade pareceu ser o bastante para atrair a atenção para esta obra em específico e daí para as outras obras com temáticas similares, entretanto, historicamente falando, os leitores não buscaram os outros textos - certamente não por falta de qualidade - por razões de natureza editorial e mercadológica. Os outros textos, aqueles desprovidos de elementos sobrenaturais, eram com frequência publicados em revista femininas (por vezes de circulação menos ampla) como Mademoiselle e Ladies Home Journal. A professora da Universidade do Mississipi, Joan Wylie Hall (1993), notou o dilema de Jackson ao tentar escrever ficção de qualidade para revistas que objetivavam vendas acima de tudo e, ao mesmo tempo, buscar resistir aos típicos enredos romanceados e adocicados que este tipo de publicação favorecia. Jackson frequentemente queria escrever sobre questões ligadas "ao racismo, ao antissemitismo e às lutas de classe" (CARPENTER, 1994, p. 68). Hall escreveu um dos livros de crítica mais importantes sobre a autora, ou seja, Shirley Jackson: A Study of the Short Fiction que, como o nome sugere, é dedicado principalmente à exploração de seus contos. $\mathrm{O}$ livro, publicado em 1993, é até hoje uma das leituras obrigatórias para os estudiosos da escritora.

Jackson nunca precisou recorrer a sangue ou a violência, ela simplesmente olhava para a humanidade e, em um tom calmo, declarava em seus escritos o que realmente assustava as pessoas, isto é, as suas próprias vidas (NOACK, 1994). Em sua ficção, Jackson demonstrava sua crítica social da maneira mais aterrorizante, e o poder genérico do conto, da maneira mais concentrada. Por motivos como esse, professores e críticos encontravam uma grande riqueza panorâmica derivada de suas observações, tanto em suas representações das ansiedades americanas em relação a gênero, classe e raça, quanto nas respostas densamente alusivas 
fornecidas por suas obras a questões de tradições populares, folclóricas e literárias (LOOTENS, 1994).

Em uma entrevista concedida à Library of America em 2010, a escritora, crítica e professora americana Joyce Carol Oates foi inquirida a respeito das razões pelas quais a publicação do conto "A Loteria" no New Yorker em 1948 havia causado tamanho furor. Sua resposta foi que:

A revista tinha a tendência de ser empertigada, pudica e afetada, com um tom irritantemente astuto. $\mathrm{O}$ conto de Jackson sugere que americanos comuns - como os leitores do New Yorker, de fato-não tem a mentalidade de tropel de linchamento tão diferente da dos nazistas. É claro que a arte de Jackson (...) é como a arte da destilação radical de Flannery O'Connor, e não da observação sutil do drama social como encontrado em Henry James, Edith Wharton, ou John Updike (LOA, 2010, p. 2).

Atenção especial deve ser dedicada ao medo da identificação com turbamultas que Oates menciona, especialmente considerando que um número razoável das cartas que Jackson e os editores da New Yorker receberam inquiriam sobre onde as ditas loterias aconteciam e se eles podiam ir até lá para vê-las. Aquela sociedade americana da metade do século $\mathrm{XX}$, do pós-guerra mais especificamente, aparentemente com alto grau de moralidade, não tinha problemas em demonstrar seu desapreço por qualquer coisa que reconhecesse como imprópria, e certamente não estava pronta para a destilação radical da realidade que os textos de Jackson traziam consigo.

Do ponto de vista psicológico, uma das principais razões para o apelo das histórias de terror é o fato de que, mesmo de maneira simbólica, elas oferecem ao leitor a chance explicitar emoções de maneira catártica que não poderiam ser exteriorizadas de outra maneira. Estórias como "A Loteria" são:

um convite a saciar a necessidade de um comportamento antissocial e depravado (...), de cometer atos gratuitos de violência, de indultar nossos sonhos pueris de poder, de ceder aos nossos medos mais enraizados. Talvez mais do que todo o resto, as histórias de terror (...) dizem que está tudo bem em unirse ao tropel, em tornar-se um ser tribal, em destruir o forasteiro. (KING, 2001, p. 43)

Em suma, o que Jackson fez foi ser uma voz importante ao "reconfigurar os tropos e convenções da literatura gótica e de horror existentes com a intenção de habilmente dissecar os costumes e as ansiedades da idade moderna" (MURPHY, 2009, p. 17). Muitos não gostavam desta catarse e, muito menos, da identificação que sentiam com os personagens dos textos de Jackson. Por isso, não é surpreendente que muitos dos 


\section{FACULDADE DE FORMAÇÃO DE PROFESSORES}

mundos ficcionais criados pela autora não fossem exatamente prazerosos, o que condizia de maneira coerente com a mensagem que ela tentava passar, isto é, que a vida naquele momento do século XX não era exatamente prazerosa; seu erro foi pintar, com suas obras, um quadro sensível demais e, principalmente, preciso demais daqueles tempos: "a falta de humanidade do homem para com o homem - a apatia por parte dos pais, a crueldade da sociedade, a perversão dos valores humanos - gritam que as visões de mundo [de Jackson] eram demasiadamente perturbadoras e realistas" (WADDEN, 1970, p. 71).

\section{Considerações finais}

Nos anos que se seguiram à sua morte, as coisas pioraram para Jackson. Esperava-se que as novas gerações de leitores e críticos finalmente enxergassem além dos textos e por fim apreciassem seu humor, sua sagacidade, seu poder de observação e crítica, seus insights sobre a vida em família, sobre como criar filhos, e sobre amizade e companhia ou a falta delas. Para a história literária, ela nunca recebeu o respeito que a literatura dita séria recebe. O resultado disto, conforme visto, foi a contração de dois estigmas: para o público leitor, que ela era apenas uma escritora de histórias sobrenaturais; para a crítica especializada, que ela não passa de uma escritora marginal. Existem, pelo menos, três linhas argumentativas que regulam o status de Jackson nas mentes dos leitores, profissionais ou não, ao longo do tempo. O primeiro, o mais pessimista, declara que ela, em momento algum, recebeu o devido reconhecimento e por isso foi "severamente negligenciada" (MURPHY, 2009, p. 17), e seu nome, "largamente esquecido" (CARPENTER, 1994, p. 67). O segundo grupo de opiniões defende que foi apenas durante o seu tempo de vida que ela recebeu mérito e nunca depois disto, isto é: "apesar de sua popularidade em vida, ela foi logo obliterada" (HWANG, 2009, p. 104). O terceiro grupo de opiniões sustenta que a associação da escritora com a vertente gótica foi o que fez com que ela mantivesse sua literatura viva, pelo menos com os consumidores deste gênero (SIEGEL, 2004) e por este motivo, "o trabalho de Jackson não desapareceu" (LOOTENS, 1994, p. 160).

Como visto anteriormente, os editores das revistas onde seus textos foram publicados tiveram sua quota de contribuição no estabelecimento e na manutenção da reputação da escritora. Quando se justapõe seus textos literários com o produto de crítica acadêmica e jornalística, 
tornam-se visíveis os esforços por partes dos editores em vender Shirley, o que "sugere como tais artimanhas auxiliaram para assegurar o sucesso imediato de Jackson e sua posterior negligência crítica" (LOOTENS, 1994, p. 160-161). Qual escritor está livre disto? Que forças invisíveis regem o destino de obras literárias? O caso de Shirley Jackson é apenas um entre muitos exemplos de historiografia literária consumadamente meritória de revisão.

\section{REFERÊNCIAS BIBLIOGRÁFICAS}

CARPENTER, Lynette. Shirley Jackson: A Study of the Short Fiction, by Joan Wylie Hall (resenha literária). South Central Review, Vol. 11, N 3, 1994, p. 67-68.

HALL, Joan Wylie. Shirley Jackson: a study of the short fiction. New York: Twayne Publishers, 1993.

HWANG, Eunju. Writing is the way out: Shirley Jackson's domestic stories and We Have Always Lived in the Castle. Feminist Studies in English Literature. Vol. 17, N. 2, 2009, p. 103-104.

KING, Stephen. Danse macabre. New York: Berkley Books, 2001.

LOA. The Library of America interviews Joyce Carol Oates about Shirley Jackson. The Library of America e-Newsletter. May 13, 2010. Disponível em: < http://www.loa.org/images/pdf/LOA_Oates_on_Jackson.pdf $>$. Acesso em: 21 jun 2011.

LOOTENS, Tricia. Shirley Jackson: a study on the short fiction (resenha literária). South Atlantic Review, Vol. 59, Nº 1, 1994, p. 160-162.

MURPHY, Bernice. The suburban gothic in American popular culture. New York: Palgrave Macmillan, 2009.

NOACK, Jennifer. Shirley Jackson - Escaping the patriarchy through insanity. Dissertação de mestrado. Charleston, IL: Eastern Illinois University, 1994, $70 \mathrm{p}$.

NORDEN, Eric. Playboy interview: Stephen King. Playboy. June 1983. Disponível em: < http://www.playboy.com/articles/playboy-interviewstephen-king/index.html?page=2 > Acesso em: 19 ago 2010.

SCHENKAR, Joan. The strange world of Stanley Edgar Hyman and Shirley Jackson. The Wall Street Journal. March 22, 2010. Disponível 


\section{FACULDADE DE FORMAÇÃO DE PROFESSORES}

em: < http://blogs.wsj.com/speakeasy/2010/03/22/the-strange-world-ofstanley-edgar-hyman-and-shirley-jackson-essay/ > . Acesso em: 13 ago. 2010 .

SIEGEL, Carolyn. Shirley Jackson's American gothic. Rocky Mountain E-Review of Language and Literature. Vol. 58. N. 2. Pullman, WA: Rocky Mountain Modern Language Association, 2004. Disponível em: < http://rmmla.wsu.edu/ereview/58.2/pdfs/58-2-2004RSiegelC.pdf > . Acesso em: 22 jun 2011.

SULLIVAN, Jack. The Haunted Mind of Shirley Jackson. Twilight Zone. August 1994, p. 71-74.

WADDEN, Jerry. Come along with me into a world of fantasy: an analysis of the illusive world of Shirley Jackson. Dissertação de mestrado. Drake University, 1970, 76 p.

WALKER, Barbara G. The Woman's Encyclopedia of Myths and Secrets. San Francisco: Harper Collins, 1983. 